\title{
Erratum zu: Einflussfaktoren und Folgen des Ausfalls gesetzlicher Ruhepausen bei Pflegekräften in Deutschland
}

\author{
Andrea Lohmann-Haislah ${ }^{1} \cdot J$ Johannes Wendsche ${ }^{2} \cdot$ Anika Schulz $^{3}$ Ina Schöllgen ${ }^{3}$ Luis Carlos Escobar Pinzon ${ }^{4}$ \\ Online publiziert: 5. März 2020 \\ (c) Der/die Autor(en) 2020
}

\section{Erratum zu:}

Z. Arb. Wiss. (2019) 73:418-438

https://doi.org/10.1007/s41449-019-00173-y

Der Artikel „Einflussfaktoren und Folgen des Ausfalls gesetzlicher Ruhepausen bei Pflegekräften in Deutschland" von Andrea Lohmann-Haislah, Johannes Wendsche, Anika Schulz, Ina Schöllgen und Luis Carlos Escobar Pinzon wurde ursprünglich ohne „Open Access“ Online First auf der Internetplattform des Verlags publiziert. Nach der Veröffentlichung im Band 73 Heft 4 pp 418-438 entschieden sich die Autoren nachträglich für eine „Open Access"-Veröffentlichung. Das Urheberrecht des Artikels wurde deshalb zu (C) Der/die Autor(en) 2020 geändert. Der Artikel wird nun unter der Namensnennung 4.0 International (https://creativecommons.org/licenses/by/4.0/deed.de) veröffentlicht, welche die Nutzung, Vervielfältigung, Bearbeitung, Verbreitung und Wiedergabe in jeglichem Medium und Format erlaubt, sofern Sie den/die ursprünglichen Autor(en) und die Quelle ordnungsgemäß nennen, einen Link zur Creative Commons Lizenz beifügen und angeben, ob Änderungen vorgenommen wurden.

Der Originalbeitrag wurde korrigiert.

Die Online-Version des Originalartikels ist unter https://doi.org/ 10.1007/s41449-019-00173-y zu finden.

\footnotetext{
Dipl.-Psych. Andrea Lohmann-Haislah

lohmann-haislah.andrea@baua.bund.de

Dr. Johannes Wendsche

wendsche.johannes@baua.bund.de

Anika Schulz, M.Sc.

schulz.anika2@baua.bund.de

Dr. Ina Schöllgen

schoellgen.ina@baua.bund.de
}

PD Dr. Luis Carlos Escobar Pinzon

EscobarPinzon.LuisCarlos@baua.bund.de
Open Access Dieser Artikel wird unter der Creative Commons Namensnennung 4.0 International Lizenz veröffentlicht, welche die Nutzung, Vervielfältigung, Bearbeitung, Verbreitung und Wiedergabe in jeglichem Medium und Format erlaubt, sofern Sie den/die ursprünglichen Autor(en) und die Quelle ordnungsgemäß nennen, einen Link zur Creative Commons Lizenz beifügen und angeben, ob Änderungen vorgenommen wurden.

Die in diesem Artikel enthaltenen Bilder und sonstiges Drittmaterial unterliegen ebenfalls der genannten Creative Commons Lizenz, sofern sich aus der Abbildungslegende nichts anderes ergibt. Sofern das betreffende Material nicht unter der genannten Creative Commons Lizenz steht und die betreffende Handlung nicht nach gesetzlichen Vorschriften erlaubt ist, ist für die oben aufgeführten Weiterverwendungen des Materials die Einwilligung des jeweiligen Rechteinhabers einzuholen.

Weitere Details zur Lizenz entnehmen Sie bitte der Lizenzinformation auf http://creativecommons.org/licenses/by/4.0/deed.de.
1 Gruppe 3.5 Psychische Belastungen, Bundesanstalt für Arbeitsschutz und Arbeitsmedizin, Nöldnerstraße 40-42, 10317 Berlin, Deutschland

2 Gruppe 3.6 Betriebliche Intervention und Transfer, Bundesanstalt für Arbeitsschutz und Arbeitsmedizin, Fabricestr. 8, 01099 Dresden, Deutschland

3 Gruppe 3.4 Mentale Gesundheit und Kognitive Leistungsfähigkeit, Bundesanstalt für Arbeitsschutz und Arbeitsmedizin, Nöldnerstraße 40-42, 10317 Berlin, Deutschland

4 Fachbereich 3 Arbeit und Gesundheit, Bundesanstalt für Arbeitsschutz und Arbeitsmedizin, Nöldnerstraße 40-42, 10317 Berlin, Deutschland 